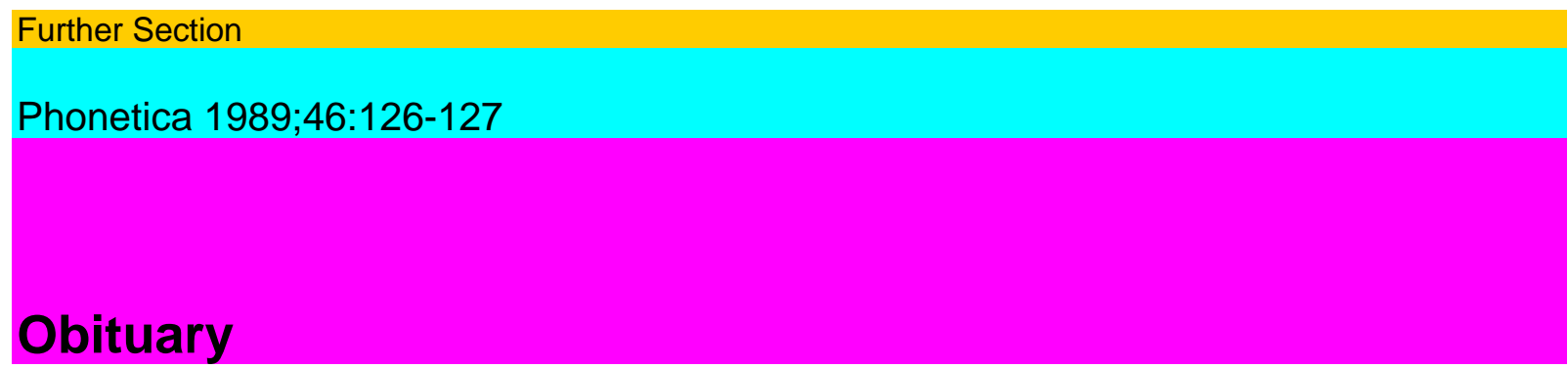

\title{
Dennis Klatt
}

Dennis H. Klatt, a noted researcher in speech and hearing science, died in Cambridge, Mass., on December 30, 1988, after a long struggle with cancer.

A graduate in electrical engineering at Purdue University in 1961, Dennis did his graduate work at the University of Michigan, where he was awarded his PhD in communication sciences in 1964. He joined the Massachusetts Institute of Technology as an assistant professor in 1965, becoming a Senior Research Scientist in 1978.

An author of more than 60 scientific pa-

pers, Dennis was working on a book on acoustic-phonetic characteristics of English at the time of his death. He recently was awarded the Silver Medal in Speech Communication by the Acoustical Society of America for 'fundamental and applied contributions to the synthesis and recognition of speech', and the John Price Wetherill Medal by the Franklin Institute, both in 1987.

Dennis' fundamental contributions to an understanding of human speech processes covered a broad range of topics. He had a

Obituary

127

continuing interest in the problem of how speech is processed in the auditory system and central nervous system of human listeners. He presented papers at international meetings on a variety of topics, including auditory processing of vowels and theories of lexical access. His work on these topics has had an important influence on the science and technology of speech recognition by machine.

The area where Dennis' work has probably had the greatest impact, at least in recent years, is speech synthesis by machine. He developed a flexible computer-based synthesizer that can generate sounds to be used as stimuli in basic studies of human speech perception. The software for his synthesizer has been available to research laboratories that are active in these areas, making possible new quantitative research on the processes of auditory and speech perception. With this synthesizer as a base, he developed a complete system for synthesis of speech from English text. His research on speech synthesis has led to a detailed specification of rules for segmental durations in English. Throughout his career Dennis retained a keen interest in seeing the results of his work applied to the special needs of blind and other handicapped persons. In addition to his significant research contributions, Dennis gave much to the students at MIT. He developed and taught a laboratory subject that gives students in engineering and linguistics a thorough grounding in experimental methods in speech communication. He was an important influence in the training of a number of graduate students, serving on dissertation committees in several departments at MIT. His integrity, his high standards, and his quiet competence were an example to his colleagues and his students. The scientific level of the field of phonetics has been enhanced by his experimental and theoretical achievements. 
Naturally quiet and sensitive, Dennis harbored a deep aversion to prejudice or intolerance of any sort and he remained a committed supporter of the American Civil Liberties Union throughout his life. For relaxation, Dennis loved to do elaborate home repair projects, play tennis and squash, paint and listen to Mozart. Dennis is survived by his wife Mary of Brookline, Mass., his daughter Laura, a sophomore at Wesleyan University, his mother Dorothy and brother Gary, both of Whitewater, Wise.

K. Stevens, Cambridge, Mass.

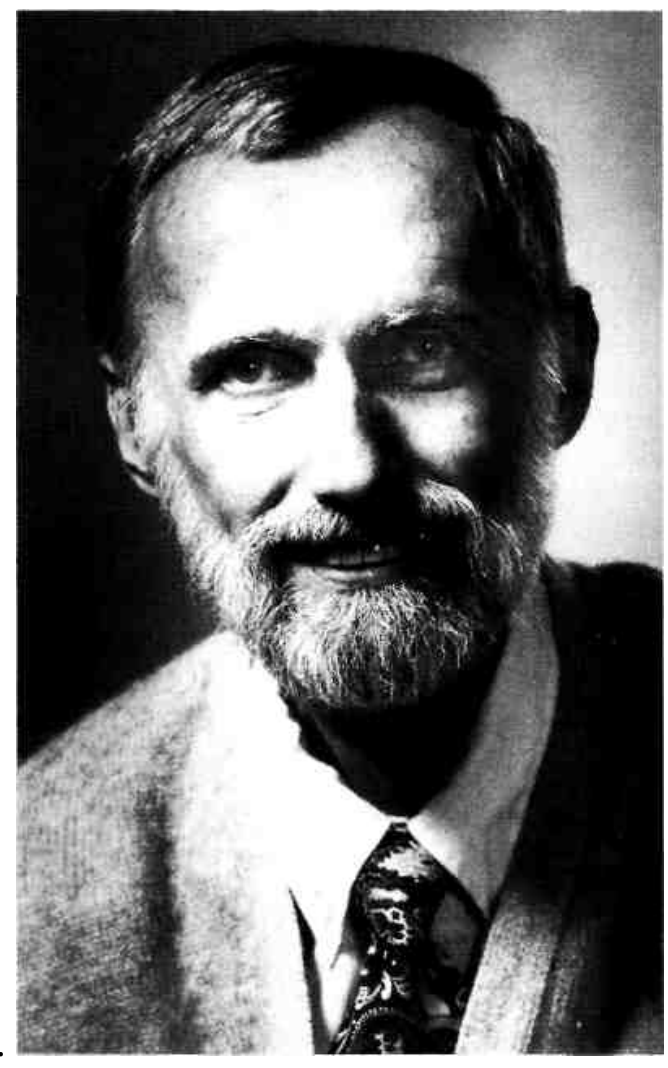

